\title{
An Investigation of Interpersonal Problem Solving in University Students in Terms of Personality Traits, Resilience and Hope
}

\author{
Sabahattin Çam \\ Çukurova University, Adana, Turkey \\ Ahmet Alkal \\ Bingöl University, Bingöl, Turkey
}

Doi: 10.19044/ejes.v7no1a2

URL:http://dx.doi.org/10.19044/ejes.v7no1a2

\begin{abstract}
This study's goal is to examine the relationship between interpersonal problem-solving approaches and personality traits, resilience, and hope levels in university students. Four hundred and one [234 (58.4\%) female, 167 (41.6\%) male] university students participated in the study. The data were collected using the Interpersonal Problem Solving Inventory, Big Five Inventory, Brief Resilience Scale, and Dispositional Hope Scale. In the study, the relationship between the variables was examined by correlation analysis. Hierarchical regression analysis was conducted to determine the predictability of personality traits, resilience, and hope on interpersonal problem-solving approaches. As a result of the study, a significant positive relationship was identified between approaching problems in a negative way, the lack of selfconfidence, and unwillingness to take responsibility and neuroticism, while a significant negative relationship was found between extraversion, agreeableness, responsibility, openness to experiences, resilience, and hope. On the other hand, a significant negative relationship was observed between constructive problem solving and the insistent-persevering approach and neuroticism, while a significant positive relationship was found between extraversion, agreeableness, responsibility, openness to experiences, resilience, and hope. Furthermore, it was determined that neuroticism and resilience significantly explain approaching problems in a negative way; agreeableness, responsibility, openness to experiences, and hope significantly explain constructive problem solving; agreeableness, responsibility, and hope significantly explain the lack of self-confidence; the personality traits of neuroticism and agreeableness significantly explain unwillingness to take responsibility; and agreeableness, openness to experiences, and hope significantly explain the insistent-persevering approach.
\end{abstract}


Keywords: Interpersonal problem solving; Personality traits; Resilience; Hope.

\section{Introduction}

An individual, a social living being, experiences conflict due to many reasons in his/her life. Interpersonal conflict is a natural and inevitable part of human life and relationships since the perspectives, thoughts, and value judgments of individuals differ (Çam \&Tümkaya, 2008). Interpersonal conflict is defined as interpersonal interaction expressing opposite views or ideas, and it is stated that interpersonal conflict expresses the interpersonal problem situation. Interpersonal problem solving is defined as a cognitive and behavioral process, in which the difference between the current situation and the situation desired to be reached in the interpersonal relationships is perceived and which involves efforts to eliminate the tension caused by this (Çam \& Tümkaya, 2007).

It is stated that individuals can use various interpersonal problemsolving approaches and skills in case of experiencing interpersonal problems or conflict (Johnson \& Johnson, 1996). According to the study conducted by Çam and Tümkaya (2007) who evaluate interpersonal problem solving within the scope of social problem solving, there are five dimensions of interpersonal problem solving, including approaching problems in a negative way, constructive problem solving, the lack of self-confidence, unwillingness to take responsibility, and insistent-persevering approach. In the case of interpersonal problems, negative emotions and thoughts such as pessimism, despair, and sadness constitute approaching problems in a negative way, and emotions, thoughts, and behaviors that contribute to the effective and constructive solution of a problem constitute constructive problem solving. The mistrust that individuals experience in the solution of their problems expresses the lack of self-confidence, while unwillingness to take responsibility necessary for the solution of the problem expresses not taking responsibility, and insistent-persevering thoughts and behaviors in the solution of the problem represent the insistent-persevering approach (Çam \& Tümkaya, 2007; 2008).

Which one of the above-mentioned approaches will be used in the process of interpersonal problem solving may be influenced by many factors. One of the factors that determine the interpersonal problem-solving approaches of individuals can be thought to be personality traits because personality traits affect many behaviors of individuals, and individuals with different personality traits use different conflict resolution strategies (Park \& Antonioni, 2007). Furthermore, many studies indicate personality traits as the determinant of interpersonal problem-solving approaches (Arslan, 2016; 
Dündar, 2009; D’Zurilla, Maydeu-Olivares \& Gallardo-Pujol, 2011; Isaksen, Kaufmann \& Bakken, 2016; Jaffee \& D'Zurilla, 2009; Koruklu, 2015; McMurran, Egan, Blair \& Richardson, 2001). Personality is defined as consistent behavior patterns originating from the individual and in-person processes (Burger, 2006). There are many theories in the literature on explaining personality, and it is observed that the five-factor personality traits approach that focuses on individual differences and observable behaviors comes to the fore. This approach reveals a five-factor personality structure, including extraversion, neuroticism, agreeableness, responsibility, and openness to experiences (Costa \& McCrae, 1995).

It is stated that university students are in the developmental period of adulthood and may experience various interpersonal problems during this period (Arnett, 2000). Interpersonal problems may influence the physical, mental, and social health of students. Resilience is stated to be an important factor that protects against the adverse effects of interpersonal problems and presents effective coping skills (McGillivray \& Pidgeon, 2015; Zhao, Guo, Suhonen \& Leino-Kilpi, 2016). Furthermore, some studies reveal the positive relationship between problem solving and resilience (Diker-Çoşkun, Garipağaoğlu \& Tosun, 2014; Samsari \& Soulis, 2019). Resilience is defined as the individual's adaptability and coping ability with negative experiences (Block \& Kremen, 1996; Masten, 2001). Resilience is a dynamic process with risks and protective factors. Risk factors are variable, and adverse life events (Masten, Best \& Garmezy, 1990) and conflicts experienced (Durlak, 1998) are stated to express personal risks. On the other hand, it is indicated that effective communication skills and healthy interpersonal relationships constitute internal protective factors (Olsson, Bond, Burns, Vella-Brodrick \& Sawyer, 2003).

In addition to the personal factors mentioned above, hope also has a significant impact on coping with problems that individuals encounter in their daily lives because hope makes it easier to solve problems and cope with loneliness (Snyder, Feldman, Taylor, Schoeder \& Adams, 2000). At the same time, it is stated that people with high levels of hope focus on the purpose rather than failure and trust adaptive coping strategies in case of a possible problem (Snyder, Harris, Anderson, Holleran, Irving, Sigmon, Yoshinobu, Gibb, Langelle \& Harney, 1991). Hope is addressed as a cognitive and motivational structure that reflects the perceptions of individuals of their capacities. This structure has two dimensions, pathways and agency. Agency is defined as wanting to reach the goal and feeling the power to reach the goal. The pathways dimension contains the individual's beliefs about himself/herself in making plans and finding different ways to reach his/her goals (Cheavens, Feldman, Woodward \& Snyder, 2006; Snyder, 2002). 
It is essential to determine personal traits and psychological factors that will contribute to the effective coping of university students with interpersonal problems because it is expected that mental health specialists working at the psychological counseling centers of universities can obtain information that will shed light on studies to be conducted on students experiencing interpersonal problems by examining the factors that affect the interpersonal problem-solving approaches of university students. Moreover, it is of great importance to determine factors that affect the interpersonal problem-solving approaches of university students in a Turkish sample because, according to the data of the Council of Higher Education, approximately 7.5 million university students were receiving formal education in Turkey in 2018 (Counc1l of Higher Education [CHE], 2018). Therefore, these research findings may constitute a resource for determining psychological factors that contribute to the positive interpersonal problem-solving approaches and skills in case of experiencing possible interpersonal problems by university students and preventive studies to be carried out in this field. Furthermore, there are no studies in which personality traits, resilience, and hope were addressed together as the variables observed to be related to interpersonal problem solving. Thus, it is thought that this study can contribute to the accumulation of knowledge and literature on interpersonal problem solving. This study was conducted to determine the relationship between the interpersonal problemsolving approaches of university students and their personality traits, resilience, and hope levels.

\section{Method}

\section{Participants and procedure}

A convenience sampling method was used in this study. Four hundred and one [234 women (58.4\%), 167 men (41.6\%)] volunteer students studying at a university in the Eastern Anatolia Region of Turkey participated in the study. The age range of the participants was between 18 and 34, the age mean was 21.24 years, and the standard deviation of the ages was 2.08. Of the participants, $193(48.1 \%)$ study in formal education programs in the second grade and $208(51.9 \%)$ in the third grade. The questionnaires were administered to classroom groups (60 to 80 students) in the classroom. Any promise of reward was not given to the participants. It took about 30 to $35 \mathrm{~min}$ for each participant to complete the measures.

\section{Measures}

Interpersonal Problem Solving Inventory: This inventory was developed by Çam and Tümkaya (2007) to measure problem-solving approaches and skills among university students with the age range of 18-30 years. The IPSI consists of 50 items and five subscales: approaching problems 
in a negative way (e.g., I feel helpless when I have a problem), constructive problem solving (e.g., I try to find more than one solution to solve a problem), the lack of self-confidence (e.g., When I have a problem, I can't change my situation no matter what I do for a solution), unwillingness to take responsibility (e.g., When I have a problem with someone I do not try to change the situation unless the other party apologizes), and the insistentpersevering approach (When I have a problem in my interpersonal relationships, I absolutely try to solve the problem). Each item is rated in the range of 1 (strongly disagree) and 5 (strongly agree). Cronbach's alpha for the IPSI subscales ranged from .67 to .91.

Big Five Inventory: Developed by Benet-Martinez and John (1998) and adapted to Turkish by Sümer and Sümer (2005), the inventory consists of 44 five-point Likert-type items and five sub-dimensions: extraversion, neuroticism, agreeableness, responsibility, and openness to experiences. The items of the scale are scored as "Disagree strongly" (1 point), "Disagree a little" (2 points), "Neither agree nor disagree" (3 points), "Agree a little" (4 points), "Agree strongly" (5 points). Cronbach's alpha coefficients of the subscales for the sample, according to which Turkey is also in the Middle East, were found to be .74 for extraversion, .76 for neuroticism, .67 for agreableness, .77 for responsibility, and .75 for openness to experiences.

Brief Resilience Scale: Resilience was measured by the Brief Resilience Scale (BRS; Smith et al., 2008), which was designed to assess the ability to bounce back or recover from stress. The BRS is a 6-item Likert-type scale (I tend to bounce back quickly after hard times). Responses were made on a 5-point Likert-type scale ( $1=$ Strongly disagree, and $5=$ Strongly agree $)$. Higher scores indicate greater resilience. The Turkish version of the BRS was adopted by Doğan (2015). Doğan reported that the Turkish version of the BRS had acceptable reliability (Cronbach's alpha: 0.83 ) and validity (CFA: $\chi 2 / \mathrm{df}=$ $1.83, \mathrm{NFI}=0.99, \mathrm{NNFI}=0.99, \mathrm{CFI}=0.99, \mathrm{IFI}=0.99, \mathrm{RFI}=0.97, \mathrm{GFI}=0.99$, $\mathrm{AGFI}=0.96$, RMSEA $=0.05$, and $\mathrm{SRMR}=0.03$ ).

Dispositional Hope Scale: Hope was measured by the Dispositional Hope Scale (DHS; Snyder et al., 1991), which was designed to assess an individual's general or characteristic level of hope. The DHS is a 12-item scale including a four filler items questionnaire that generates scores based on two subscales: agency (e.g. my past experiences have prepared me well for my future) and pathway (e.g. I can think of many ways to get the things in life that are important to me). Responses were made on an 8-point Likert-type scale (1 $=$ Definitely false and $8=$ Definitely true). Higher scores indicate greater hope. The Turkish version of the DHS was adopted by Tarhan and Bacanlı (2015). Tarhan and Bacanlı reported that the Turkish version of the DHS had acceptable reliability (Cronbach's alpha: 0.84) and validity (CFA: GFI $=0.96$, $\mathrm{AGFI}=0.92, \mathrm{NNFI}=0.94, \mathrm{RFI}=0.90 \mathrm{CFI}=0.96$, and $\mathrm{RMSEA}=0.077$ ). 


\section{Data analysis}

Correlation analysis and hierarchical regression analysis were performed using the IBM SPSS Statistics 22 program in the analysis of the data. It is stated that skewness and kurtosis values between +1.5 and -1.5 are sufficient criteria for the data to show normal distribution (Tabachnick \& Fidell, 2013). When the skewness and kurtosis values of the variables in Table 2 are examined, it can be said that the distribution of the points of the variables provides the assumption of normality. Hierarchical regression analysis was conducted to determine whether the interpersonal problem-solving approaches of university students were predicted by personality traits, resilience, and hope. We reviewed the suitability of the data for regression analysis. Firstly, the ratio of the number of participants (401) included in the data set to the number of independent variables (7) was determined to be 57.28 to determine the sample size. This value meets the criteria of Tabachnick and Fidel (2013), according to which the ratio of the number of data/number of independent variables determined for the sample size should be 40/1. Secondly, the relationship between interpersonal problem solving and predictive variables was determined by scattering diagrams, which are linear. Furthermore, histogram and normal distribution graphs revealed that the data did not show significant deviations from normality. Thirdly, for the multivariate normality assumption, the Mahalanobis distance values were determined, and it was observed that there were no data above the distance values criterion values [according to $\mathrm{x} 2(7)=23.61, \mathrm{p}=.001$ ]. Fourthly, to determine whether there were multiple linear connections between the continuous variables of the study, the Pearson correlation coefficients were calculated, and the obtained coefficients were between -.53 and .58 . These correlation coefficients show that there are no multiple connection problems between the variables examined in the study (Montgomery, Peck \& Vining, 2014).

\section{Results}

In accordance with the purpose of the study, firstly, correlation analysis was performed to determine the relationship between the interpersonal problem-solving approaches and skills of university students and their personality traits, resilience, and hope levels, and the results are presented in Table 1. Then, the dimensions of interpersonal problem solving were addressed separately, and hierarchical regression analysis was conducted to reveal which ones of the predictive variables and to what extent were explained by personality traits, resilience, and hope. While performing regression analysis, the personality traits in the first model were entered into the analysis, and resilience in the second model and hope in the third model were included in the analysis. The results obtained in the analysis are presented in Table 2. 
A significant positive relationship was found between approaching problems in a negative way, the lack of self-confidence, and unwillingness to take responsibility and neuroticism (between $\mathrm{r}=.18, .51$ ), and a significant negative relationship was found between extraversion, agreeableness, responsibility, openness to experiences, resilience, and hope (between $\mathrm{r}=$ $-.15,-.53)$. On the other hand, a significant negative relationship was determined between constructive problem solving and the insistentpersevering approach and neuroticism (between $\mathrm{r}=-.17,-.27$ ), and a significant positive relationship was identified between extraversion, agreeableness, responsibility, openness to experiences, resilience, and hope (between r=.17, .49). Furthermore, no significant relationship was found between approaching problems in a negative way and agreeableness (Table 1).

Table 2. Hierarchical Regression Analysis Results Regarding Prediction of Interpersonal Problem Solving

\begin{tabular}{|c|c|c|c|c|c|c|c|c|c|c|c|c|c|c|c|c|c|c|c|c|c|c|c|c|c|c|}
\hline \multirow{2}{*}{ 胥 } & \multirow{2}{*}{$\begin{array}{l}\text { Predictor } \\
\text { Variables }\end{array}$} & \multicolumn{5}{|c|}{ APN } & \multicolumn{5}{|c|}{ CPS } & \multicolumn{5}{|c|}{ LSC } & \multicolumn{5}{|c|}{ UTR } & \multicolumn{5}{|c|}{ I-PA } \\
\hline & & B & $\beta$ & $\mathrm{t}$ & $\mathrm{R}^{2}$ & $\Delta \mathbf{R}^{2}$ & B & $\beta$ & $t$ & $\mathbf{R}^{2}$ & $\Delta \mathrm{R}^{2}$ & B & $\beta$ & $t$ & $\mathbf{R}^{2}$ & $\Delta \mathbf{R}^{2}$ & B & $\beta$ & $t$ & $\mathrm{R}^{2}$ & $\Delta \mathbf{R}^{2}$ & B & $\beta$ & $t$ & $\mathrm{R}^{2}$ & $\Delta \mathbf{R}^{2}$ \\
\hline \multirow{6}{*}{1} & Constant & 20.05 & & $3.12 *$ & \multirow{6}{*}{.28} & \multirow{6}{*}{.27} & 13.45 & & $2.56^{*}$ & \multirow{6}{*}{.31} & \multirow{6}{*}{30} & 24.93 & & $9.02 *$ & \multirow{6}{*}{.12} & \multirow{6}{*}{11} & 18.23 & & $7.57^{*}$ & \multirow{6}{*}{.11} & \multirow{6}{*}{.10} & 7.21 & & $3.11^{*}$ & \multirow{6}{*}{.16} & \multirow{6}{*}{.15} \\
\hline & E & -.25 & -.10 & $-2.25 *$ & & & .13 & .06 & 1.48 & & & -.08 & -.08 & -1.68 & & & -.06 & -.08 & -1.60 & & & .05 & .07 & 1.39 & & \\
\hline & $\mathbf{N}$ & 1.12 & .47 & $10.27^{*}$ & & & -.19 & -.09 & $-2.15^{*}$ & & & .06 & .07 & 1.46 & & & .12 & .15 & $2.96 *$ & & & -.02 & -.03 & -.74 & & \\
\hline & A & .22 & .08 & 1.85 & & & .36 & .17 & $3.66^{*}$ & & & -.14 & -.14 & $-2.83^{*}$ & & & -.15 & -.18 & $-3.50^{*}$ & & & .13 & .15 & $3.03^{*}$ & & \\
\hline & R & -.11 & -.05 & -1.00 & & & .37 & .19 & $3.89 *$ & & & -.17 & -.18 & $-3.34^{*}$ & & & -.07 & -.09 & -1.62 & & & .10 & .14 & $2.55^{*}$ & & \\
\hline & $\mathrm{OE}$ & -.07 & -.03 & -.62 & & & .48 & .27 & $5.31^{*}$ & & & -.01 & -.01 & -.32 & & & .00 & .00 & .08 & & & .12 & .17 & $3.17^{*}$ & & \\
\hline \multirow{7}{*}{2} & Constant & 43.51 & & $6.40^{*}$ & \multirow{7}{*}{.36} & \multirow{7}{*}{.36} & 6.25 & & 1.06 & \multirow{7}{*}{.32} & \multirow{7}{*}{.31} & 26.94 & & $8.64^{*}$ & \multirow{7}{*}{.13} & & 19.94 & & $7.34^{*}$ & & & 5.37 & & $2.06^{*}$ & & \\
\hline & E & -.06 & -.02 & -.58 & & & .08 & .04 & .83 & & & -.06 & -.07 & -1.31 & & & -.05 & -.06 & -1.24 & & & .04 & .05 & 1.00 & & \\
\hline & $\mathbf{N}$ & .73 & 30 & $6.35 *$ & & & -.07 & -.03 & -.72 & & & .03 & .03 & .67 & & & .09 & .11 & $2.02 *$ & & & .00 & .00 & .02 & & \\
\hline & A & .16 & .06 & 1.41 & & & .37 & .17 & $3.87^{*}$ & & & -.15 & -.15 & $-2.93 *$ & & .11 & -.16 & -.18 & $-3.59^{*}$ & .12 & .11 & .13 & .16 & $3.14^{*}$ & .17 & .16 \\
\hline & $\mathbf{R}$ & -.12 & -.05 & -1.12 & & & .37 & .19 & $3.94^{*}$ & & & -.17 & -.18 & $-3.36^{*}$ & & & -.07 & -.09 & -1.63 & & & .10 & .14 & $2.56^{*}$ & & \\
\hline & $\mathrm{OE}$ & -.05 & -.02 & -.47 & & & .48 & .26 & $5.28 *$ & & & -.01 & -.01 & -.28 & & & .00 & .00 & .12 & & & .12 & .17 & $3.13^{*}$ & & \\
\hline & Resilience & -.97 & -.35 & $-7.41^{*}$ & & & .29 & .13 & $2.63^{*}$ & & & -.08 & -.07 & -1.38 & & & -.07 & -.07 & -1.35 & & & .07 & .08 & 1.51 & & \\
\hline & Constant & 43.76 & & $6.44^{*}$ & & & 5.49 & & 95 & & & 27.24 & & $8.85^{*}$ & & & 19.95 & & $7.33^{*}$ & & & 5.19 & & $2.00^{*}$ & & \\
\hline & E & -.05 & -.02 & -.52 & & & .05 & .02 & .63 & & & -.05 & -.06 & -1.16 & & & -.05 & -.06 & -1.22 & & & .03 & .04 & .89 & & \\
\hline & $\mathbf{N}$ & .73 & 30 & $6.34 *$ & & & -.06 & -.03 & -.67 & & & .03 & -.03 & .62 & & & .09 & 11 & $2.01^{*}$ & & & .00 & .00 & .06 & & \\
\hline 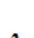 & A & .18 & .07 & 1.57 & 27 & 27 & 31 & .15 & $3.31^{*}$ & 25 & 2 & -.12 & -.12 & $-2.48^{*}$ & 15 & 1 & -.16 & -.18 & $-3.53^{*}$ & 18 & 10 & .12 & .14 & $2.80 *$ & 10 & 17 \\
\hline 3 & R & -.08 & -.03 & -.73 & 31 & .37 & .25 & .13 & $2.66^{*}$ & .35 & .34 & -.12 & -.13 & $-2.36 *$ & .17 & .14 & -.07 & -.09 & $-1,52$ & 112 & .10 & .08 & .10 & 1.83 & .18 & .17 \\
\hline & $\mathrm{OE}$ & -.01 & -.00 & -.13 & & & .37 & .21 & $4.09^{*}$ & & & .02 & .03 & .57 & & & .00 & .01 & .16 & & & .10 & .14 & $2.44^{*}$ & & \\
\hline & Resilience & -.92 & -34 & $-6.85^{*}$ & & & .16 & .07 & 1.45 & & & -.03 & -.02 & -.49 & & & .06 &.-07 & -1.27 & & & .04 & .04 & .85 & & \\
\hline & Hope & -.09 & -.06 & -1.28 & & & .27 & .23 & $4.55^{*}$ & & & -.11 & -.20 & $-3.40^{*}$ & & & -.00 & -.00 & -.15 & & & .06 & .14 & $2.43^{*}$ & & \\
\hline
\end{tabular}

$n=401, * * p<.01 * p<.05$, APN (Approaching Problems in a Negative Way), CPS

(Constructive Problem Solving), LSC (Lack of Self-Confidence), UTR (Unwillingness to

Take Responsibility), I-PA (Insistent-Persevering Approach), E (Extraversion), $N$

(Neuroticism), A (Agreeableness), R (Responsibility), OE (Openness to Experiences)

Agreeableness $(\beta=-.12, \mathrm{p}<.05)$, responsibility $(\beta=-13, \mathrm{p}<.05)$, and hope $(\beta=-.20, p<.05)$ significantly predict the lack of self-confidence and explain $14 \%\left(\Delta \mathrm{R}^{2}=.13\right)$ of the total variance $\left(\mathrm{F}_{(394,6)}=10.00, \mathrm{p}<.001\right)$. 
Neuroticism $(\beta=.11, p<.05)$ and agreeableness $(\beta=-.18, \quad \mathrm{p}<.05)$ significantly predict unwillingness to take responsibility and explain $10 \%$ $\left(\Delta \mathrm{R}^{2}=.10\right)$ of the total variance $\left(\mathrm{F}_{(394,6)}=7.54, \mathrm{p}<.001\right)$.

Agreeableness $(\beta=.14, p<.05)$, openness to experiences $(\beta=.14, p<.05)$, and hope $(\beta=.14, p<.05)$ significantly predict the insistent-persevering approach and explain $17 \%\left(\Delta \mathrm{R}^{2}=.17\right)$ of the total variance $\left(\mathrm{F}_{(394,6)}=12.30\right.$, $\mathrm{p}<.001)$.

\section{Discussion}

In this study, the relationship between the interpersonal problemsolving skills and approaches of university students and their personality traits, resilience, and hope levels was investigated. According to the first finding of the study, a significant positive relationship was found between approaching problems in a negative way and neuroticism, and a significant negative relationship was found between extraversion, responsibility, openness to experiences, resilience, and hope. Furthermore, neuroticism and resilience were found to be significant predictors of approaching problems in a negative way. These findings indicate that university students with a high level of neuroticism and a low level of resilience have ineffective problem-solving approaches and are consistent with the findings of previous studies (Arslan, 2016; Ertekin-Pınar, Yıldırım \& Sayın, 2018; Jaffee \& D'Zurilla, 2009). Neuroticism refers to being anxious and mistrustful (Burger, 2006). It is possible that people with a high level of neuroticism do not trust and are pessimistic about the fact that they can solve problems and easily worry when they encounter any problems (D'Zurilla \& Chang, 1995). Moreover, since they tend to pay more attention emotionally to negative events, they will likely respond negatively to interpersonal conflicts (Gunthert, Cohen \& Armeli, 1999). Therefore, it can be stated that university students with high levels of neuroticism do not trust themselves in problem solving and tend to avoid or ignore the problem instead of solving it. Furthermore, it can be said that people with high extraversion, responsibility, and openness to experiences, in terms of the personality structure, adopt approaching problems in a negative way less in interpersonal problem solving. On the other hand, it can be said that university students with low resilience are less likely to protect themselves by activating their protective mechanisms and sources of coping with challenging events they encounter (Conner \& Davidson, 2003). These results show that university students with a high level of neuroticism and a low level of resilience are less likely to cope with the problems they encounter.

As a result of the study, a significant positive relationship was found between constructive problem solving and extraversion, agreeableness, responsibility, openness to experiences, resilience, and hope, and a significant negative relationship with neuroticism was found. Furthermore, 
agreeableness, responsibility, openness to experiences, and hope were found to be significant predictors of constructive problem solving. This result obtained is consistent with the findings of the previous research (Arslan, 2016; Chang, 1998; Diker-Çoşkun, Garipağaoğlu \& Tosun, 2014; Major, Richards, Cooper, Cozarelli \& Zubek, 1998; Li \& Yang, 2009; Li \& Nishikawa, 2012; Li, Eschenauer \& Yang, 2013; Park \& Antonioni, 2007). Moreover, the personality dimensions of extraversion, agreeableness, responsibility, and openness to experiences explain constructive problem solving. Extraversion refers to being positive, social, sociable, and dominant (Moberg, 2001; Park \& Antonioni, 2007). People with high levels of extraversion adopt more constructive problem-solving approaches in case of conflict (JensenCampbell, Gleason, Adams \& Malcolm, 2003). People with a high level of agreeableness have a positive attitude toward maintaining social relationships (Jensen-Campbell \& Graziano, 2001). They attach more importance to cooperating and reaching a consensus (Moberg, 2001; Park \& Antonioni, 2007). People with high levels of responsibility maintain interpersonal relationships successfully and feel more responsibility toward their environment in case of potential conflict (Jensen-Campbell \& Malcolm, 2007). People with high levels of openness to experiences exhibit conflict resolution behaviors by facing conflict instead of avoiding conflicts (Antonioni, 1998). Furthermore, individuals with a high level of resilience exhibit positive attitudes toward the difficulties of life and take action to solve the problem (Li \& Yang, 2009; Li \& Nishikawa, 2012). People with a high level of hope rely on effective coping strategies when they face difficulties (Snyder et al., 1991). These results demonstrate that university students with high levels of agreeableness, responsibility, openness to experiences, and hope use more constructive problem-solving skills to cope with the problems they encounter.

As a result of the study, a significant positive relationship was determined between the lack of self-confidence and neuroticism, and a significant negative relationship was identified between extraversion, agreeableness, responsibility, openness to experiences, resilience, and hope. Moreover, agreeableness, responsibility, and hope were found to be significant predictors of the lack of self-confidence. Previous studies support the findings of our study. For example, Arslan (2016) determined a significant positive relationship between the lack of self-confidence and neuroticism and a significant negative relationship between extraversion, agreeableness, responsibility, and openness to experiences. Chang (1998) stated that there was a significant negative relationship between the hope levels of university students and the avoidant approach. Furthermore, in the studies conducted by Vatan and Dağ (2009) and Oğuztürk, Akça, and Şahin (2011) in the Turkish sample, the researchers revealed a significant positive relationship between 
avoidant problem-solving approaches and despair. The lack of self-confidence indicates the lack of individuals' self-confidence in solving a problem (Çam \& Tümkaya, 2007). Since neurotic individuals experience mistrust of that they can solve a problem (D'Zurilla \& Chang, 1995), they may experience the lack of self-confidence in case of a possible conflict. At the same time, mistrustful individuals are expected to have less extraversion, agreeableness, responsibility, and openness to experiences. Furthermore, it is stated that a high level of resilience is the indicator of a high level of self-confidence (Ertekin-Pınar, Yıldırım \& Sayın, 2018) and the full functioning of hope at a high level (Martin, 2007). Thus, individuals with low levels of resilience and hope may experience mistrust in themselves concerning problem solving. These results show that university students with low levels of agreeableness, responsibility, and hope will experience more mistrust concerning interpersonal problem solving.

As a result of the study, a significant positive relationship was found between unwillingness to take responsibility and neuroticism, and a significant negative relationship was found between extraversion, agreeableness, responsibility, openness to experiences, resilience, and hope. The personality traits of neuroticism and agreeableness were also found to be significant predictors of unwillingness to take responsibility. This finding indicates that university students with a high level of neuroticism and a low level of agreeableness do not take responsibility to solve interpersonal problems and is consistent with the findings of the previous studies in the literature (Arslan, 2016; Chang, 1998). Since neurotic individuals tend to avoid or ignore a problem instead of solving it (Moberg, 2001), it can be considered as an expected result that they adopt not taking responsibility instead of solving interpersonal problems. Since individuals with low levels of agreeableness are associated with hostile, competition-loving, stubborn, rude, and skeptical personality traits (Graziano, Jensen-Campbell \& Hair, 1996), it is possible that individuals with low levels of agreeableness do not take responsibility for the solution of interpersonal problems. On the other hand, individuals who adopt not taking responsibility are expected to have less extraversion, agreeableness, responsibility, and openness to experiences personality traits because it is stated that people with high levels of extraversion, agreeableness, responsibility, and openness to experiences, adopt the confrontation approach in conflict resolution due to the personality structure (Basım, Çetin \& Tabak, 2009). These results show that university students with a high level of neuroticism and a low level of agreeableness take less responsibility for the solution of interpersonal problems.

According to the final finding of the study, a significant negative relationship was found between the insistent-persevering approach and neuroticism, while a significant positive relationship was found between 
extraversion, agreeableness, responsibility, openness to experiences, resilience, and hope. Furthermore, agreeableness, openness to experiences, and hope were found to be significant predictors of the insistent-persevering approach. This finding is consistent with the findings of the previous studies in the literature (Arslan, 2016; Chang, 1998; D'Zurilla, Chang, Nottingham \& Faccini, 1998). It is stated that people with a high level of agreeableness adopt more constructive conflict resolution strategies (Jensen-Campbell, Gleason, Adams \& Malcolm, 2003), while people with a high level of openness to experiences adopt consensus and cooperation approaches among conflict resolution approaches (Moberg, 2001; Park ve Antonioni, 2007). Therefore, people with more personality traits of agreeableness and openness to experiences are likely to exhibit insistent-persevering thoughts and behaviors for the solution of interpersonal problems. It is also stated that students with a high level of hope have more problem-solving skills (Chang, 1998). These results demonstrate that university students with high levels of agreeableness, openness to experiences, and hope are insistent and patient in solving interpersonal problems.

\section{Conclusion}

The results of this study contribute to a better understanding of the relationship between interpersonal problem solving, personality traits, resilience, and hope. According to the findings, it can be said that university students with high levels of extraversion, agreeableness, responsibility, and openness to experiences and a low level of neuroticism exhibit more effective interpersonal problem solving approaches and skills in case of interpersonal problems. At the same time, it can be said that students with high levels of resilience and hope have more effective problem solving skills. On the other hand, it can be concluded that university students with a high level of neuroticism and low levels of resilience and hope adopt more negative interpersonal problem solving approaches. Moreover, it was observed that the personality traits of agreeableness and openness to experiences and hope predict interpersonal problem solving skills (CPS, I-PA). This result supports the idea that agreeableness is an important personality trait in terms of preserving and maintaining social relationships, and openness to experiences is an important personality trait in terms of reaching an effective and constructive solution of interpersonal problems. On the other hand, the fact that the personality trait of neuroticism predicts negative interpersonal problem solving approaches (APN, UTR) supports the view that individuals with this personality trait tend to avoid problems instead of solving them since they do not believe and are pessimistic about the fact that the problem can be solved. 


\section{Limitations and Future Directions}

This study has some limitations. The first limitation of this study is the collection of data by the self-report method, which may reduce the internal validity. Collecting data by using more than one method (for example, interview and observation) may help to reduce the impact of subjectivity. The second limitation is the fact that the participants consist of students of a university in the Eastern Anatolia Region of Turkey. Therefore, the generalizability of the findings of this study is limited. Conducting similar studies by using different populations and larger samples can help increase the generalizability of results. The third limitation is that the relationships observed between the predicting and predicted variables were not interpreted as casual relationships since the study was conducted with a relational screening design.

Finally, some suggestions can be made to researchers and practitioners based on the findings of this study. Regarding future research, comparative studies can be conducted by examining the interpersonal problem solving approaches and skills of individuals in different developmental periods. This study can be repeated in larger samples with more heterogeneous features in terms of interpersonal problem solving. In addition to these, qualitative studies can be carried out to obtain more in-depth information about interpersonal problem solving approaches. In studies to be conducted for improving the interpersonal relationships with university students, individual and group psychological counseling practices can be performed for interpersonal problem solving with students with a high level of neuroticism. Moreover, it can be expected that students' tendencies to approach interpersonal problems in a negative way, the lack of self-confidence, and unwillingness to take responsibility can be reduced with studies aiming to increase resilience and hope.

\section{References:}

1. Antonioni, D.(1998). Relationship between the big five and personality factors and conflict management styles. International Journal of Conflict Management, 9(4), 336-355.

2. Arnett, J.J. (2000) .Emerging adulthood: A theory of development from the late teens through the twenties. American Psychologist 55, 469- 480.

3. Arslan, Ç. (2016). Interpersonal problem solving, self-compassion and personality traits in üniversity students. Educational Research and Reviews, 11(7), 474-481.

4. Basım, H.N., Çetin, F., \& Tabak, A. (2009). The relationship between big five personality characteristics and conflict resolution approaches. Turkish Journal of Psychology, 24(63), 35-37. 
5. Block, J. \& Kremen, A.M. (1996). IQ and ego-resiliency: Conceptual and empirical connections and separateness. Journal of Personality and Social Psychology, 70(2), 349-361.

6. Burger, J.M. (2006). Identity. İstanbul: Kaknus publishing.

7. Chang, E.C. (1998). Hope, problem-solving ability and coping in a college student population: Some implications for theory and practice. Journal of Clinic Psychology, 54(7), 953-962.

8. CHE (2018). Student statistics. https://istatistik.yok.gov.tr/ (Date of Access: 06.10.2018).

9. Cheavens, J.S., Feldman, D.B.,Woodward, J.T., \& Snyder, C.R. (2006). Hope in cognitive psychotherapies: on working with client strengths. Journal of Cognitive Psychotherapy: An International Quarterly, 20(2), 135- 145.

10. Conner, K.M., \& Davidson, J.R.T. (2003). Development of a new resilience scale: The Connor-Davidson Resilience Scale (CD-RISC). Depression and Anxiety, 18, 76-82.

11. Costa, P., \& McCrae, R.R.(1995). Domains and facets: Hiyerarchical personality assessment using the revised neo personality inventory. Journal of Personality Assessment, 64(1), 21-50.

12. Çam, S., \& Tümkaya, S. (2007). Developıng the interpersonal problem solving inventory (IPSI): The validity and reliability process. Turkish Psychological Counseling and Guidance Journal, 28(3), 95-111.

13. Çam, S., \& Tümkaya, S. (2008). Validity and reliability study of interpersonal problem solving inventory high school students form. International Journal of Human Sciences, 5(2) 1-17.

14. Diker-Çoşkun, Y., Garipağaoğlu, Ç., \& Tosun, Ü. (2014). Analysis of the relationship between the resiliency revel and problem solving skills of university students. Procedia - Social and Behavioral Sciences, 114, 673-680.

15. Doğan, T. (2015). Adaptation of the Brief Resilience Scale into Turkish: A validity and reliability study. The Journal of Happiness \& Well-Being, 3(1), 93-102.

16. Durlak, J.A. (1998). Common risk and protective factors in successful prevention programs. American Journal of Orthopsychiatry, 68(4), 512-520.

17. Dündar, S. (2009). Analyzing the Relationship between Problem Solving Skills and Personality Characteristics of University Students. Dokuz Eylul University Faculty of Economics and Administrative Sciences Journal, 24(2), 139-150.

18. D'Zurilla, T.J., \& Chang, E.C. (1995). The relations between social problem solving and coping. Cognitive Therapy and Research, 19(5), 547-562. 
19. D’Zurilla, T.J., Chang, E.C., Nottingham, E. J., \& Faccini, L. (1998). Social problem-solving deficits and hopelessness, depression, and suicidal risk in college students and psychiatric inpatients. Journal of Clinic Psychology, 54(8), 1091-1107.

20. D'Zurilla, T.J., Maydeu-Olivares, A., \& Gallardo-Pujol, D. (2011). Predicting social problem solving using personality traits. Personality and Individual Differences, 50, 142-147.

21. Ertekin-Pınar, Ş., Yıldırım, G., \& Sayın, N. (2018). Investigating the psychological resilience, self-confidence and problem-solving skills of midwife candidates. Nurse Education Today, 64, 144-149.

22. Graziano, W.G., Jensen-Campbell, A.L., \& Hair, C.E. (1996). Perceiving interpersonal confl ict and reacting to it: The case for agreeableness. Journal of Personality and Social Psychology, 70, 820835.

23. Gunthert, K.C., Cohen, L.H., \& Armeli, S. (1999). The role of neuroticism in daily stress and coping. Journal of Personality and Social Psychology, 77, 1087-1100.

24. Isaksen, S.G., Kaufmann, A.H., \& Bakken, B.T. (2016). An examination of the personality constructs underlying dimensions of creative problem-solving style. Journal of Creative Behavior, 50(4), 268-281.

25. Jaffee, B.W., \& D'Zurilla, T.J. (2009). Personality, Problem Solving, and Adolescent Substance Use. Behavior Therapy, 40(1), 93-101.

26. Jensen-Campbell, L. A., \& Graziano, W. G. (2001). Agreeableness as a moderator of interpersonal conflict. Journal of Personality, 69(2), 323-362.

27. Jensen-Campbell, L.A., \& Malcolm, K.T. (2007). The importance of conscientiousness in adolescent interpersonal relationships. Personality and Social Psychology Bulletin, 33(3), 368-383.

28. Jensen-Campbell, L.A., Gleason, K.A., Adams, R., \& Malcolm, K.T. (2003). Interpersonal conflict, agreeableness, and personality development. Journal of Personality, 71(6), 1060-1085.

29. Johnson, D.W., \& Johnson, R.T. (1996). Conflict resolution and peer mediation programs in elementary and secondary schools: A review of the research. Review of Educational Research, 66(4), 459-506.

30. Koruklu, N. (2015). Personality and social problem-solving: The mediating role of self-esteem. Educational Sciences: Theory \& Practice, 15(2), 481-487.

31. Li, M.H., \&Yang, Y. (2009). Determinants of problem solving, social support-seeking, and avoidance: Apath analytic model. International Journal of Stress Management, 16, 155-176. 
32. Li, M.H., \& Nishikawa, T. (2012). The relationship among active coping and trait resilience across U.S. and Taiwanese college student samples. Journal of College Counseling, 15, 157171.

33. Li, M.H., Eschenauer, R., \& Yang, Y. (2013). Influence of Efficacy and Resilience on Problem Solving in the United States, Taiwan, and China. Journal of Multicultural Counseling and Development, 41, 144-157.

34. Major, B., Richards, C., Cooper, M.L., Cozarelli, C., ve Zubek, J. (1998). Personal resilience, cognitive appraisals, and coping: An Integrative model of adjustment to abortion. Journal of personality and Social Psychology, 74(3), 735-752.

35. Martin, K.K. (2007). Measuring hope: Is hope related to problem solving and criminal behaviour in offenders? (Master's thesis). University of Toronto, Toronto.

36. Masten, A. S. (2001). Ordinary magic: Resilience processes in development. American Psychologist, 56, 227-238.

37. Masten, A.S., Best, K.M., \& Garmezy, N. (1990). Resilience and development: Contributions from the study of children who overcome adversity. Development and Psychopathology, 2, 425-444.

38. McGillivray, C.J., \& Pidgeon, A.M. (2015). Resilience attributes among university students: A comparative study of psychological distress, sleep disturbances and mindfulness. European Scientific Journal, 11 (5), 33-48.

39. McMurran, M., Egan, V., Blair, M., \& Richardson, C. (2001). The relationship between social problem solving and personality in mentally disordered offenders. Personality and Individual Differences, 30, 517-524.

40. Moberg, P.J. (2001). Linking confl ict strategy to the fi vefactor model: Theoretical and empirical foundations. International Journal of Confl ict Management, 12(1), 47-22.

41. Montgomery, D.C., Peck, E.A., \& Vining, G.G. (2014). Introduction to linear regression analysis, (5th ed). New Jersey: Wiley.

42. Oğuztürk, Ö., Akça, F., \& Şahin, G. (2011). Investigation of Relationship Between Hopeless Level and Problem Solving Skills in the Aspects of Some Variables. The Turkish Journal of Clinical Psychiatry, 14, 85-93.

43. Olsson, C.A., Bond, L., Burns, J.M., Vella-Brodrick, D.A., \& Sawyer, S.M. (2003). Adolescent resilience: A concept analysis. Journal of Adolescence, 26(1), 1-11.

44. Park, H., \& Antonioni, D. (2007). Personality, reciprocity and strength of confl ict resolution strategy. Journal of Research in Personality, 41, $110-125$. 
45. Samsari, E.P., \& Soulis, S.G. (2019). Problem solving and resilience self-efficacy as factors of subjective well-being in greek individuals with and without physical disabilities. International Journal of Special Education, 33(4), 938-953.

46. Snyder, C.R. (2002). Hope theory: Rainbows in the mind. Psychological Inquiry, 13(4), 249-275.

47. Snyder, C.R., Feldman, D. B.,Taylor, J.D., Schoeder, L.L., \& Adams, V.H. (2000). The roles of hopeful thinking in preventing problems and enhancing strengths. Applied and Preventive Psychology, 9(4), 249269.

48. Snyder, C. R., Harris, C., Anderson, J. R., Holleran, S. A., Irving, L. M., Sigmon, S. T., Yoshinobu, L., Gibb, J., Langelle, C., \& Harney, P. (1991). The will and ways: Development and validation of an individual-differences measure of hope. Journal of Personality and Social Psychology, 60(4), 570- 585.

49. Sümer, N., \& Sümer, H. C. (2005). Five-factor personality traits scale (Unpublished study).

50. Tabachnick, B.G., \& Fidell, L.S. (2013). Using multivariate statistics, (6th ed.) Boston: Pearson.

51. Tarhan, S., \& Bacanl1, H. (2015). Adaptation of Dispositional Hope Scale into Turkish: Validity and reliability study. The Journal of Happiness \& Well-Being, 3(1), 1-14.

52. Vatan, S., \& Dağ, İ. (2009). Problem solving style, hopelessness, helplessness and haplessness as the predictors of psychopathology assessed by MMPI-2. Anatolian Journal of Psychiatry, 10, 187-197.

53. Zhao, F.F., Guo, Y., Suhonen, R., \& Leino-Kilpi, H. (2016). Subjective well-being and its association with peer caring and resilience among nursing vs medical students: A questionnaire study. Nurse Education Today, 37, 108-113 